\title{
BALANCO HIDRICO DE ITUVERAVA(SP) SOB CONDIÇÕES DE CENÁRIOS CLIMÁTICOS FUTUROS
}

GARCIA, Anice ${ }^{1}$

Recebido em: 2009.08 .28

Aprovado em: 2010.03.29

ISSUE DOI: $10.3738 / 1982.2278-295$

RESUMO: O objetivo do presente trabalho foi avaliar o balanço hídrico climatológico para Ituverava - SP, para três condições distintas: o BHC normal, com dados de 12 anos, o BHC com dados simulados de mudanças climáticas, em que adotou-se os cenários A2 - o mais pessimista, que estima um aumento de temperatura de $4,0^{\circ} \mathrm{C}$ até 2100 - e o B2 - um pouco mais otimista, que prevê um aumento de temperatura de até $2,0^{\circ} \mathrm{C}$ em 2100 . Com relação a precipitação, adotou-se as previsões de $-10 \%$ de precipitação durante o inverno e $+5 \%$ de precipitação durante o verão, baseados no quarto relatório de avaliação do IPCC (2007). Para os situações propostas, concluiu-se que o clima estará mais quente e a estiagem será mais longa. E embora os prognósticos sejam de um aumento no total de precipitação durante o verão, o aumento da temperatura provocará um aumento dos níveis de evapotranspiração, que não conseguirão ser supridos com a precipitação ocorrida, aumentando o déficit hídrico. Assim, medidas deverão ser adotadas para um planejamento do uso e ocupação agrícola das terras, bem como do manejo sustentável da água.

Palavras Chave: IPCC. Mudanças climáticas. Agricultura. Manejo de água.

SUMMARY: The objective of this work was to evaluate the water budget (BHC) for Ituverava - SP, for three different conditions: acutal BHC, BHC with simulate data of climatic changes, in that was adopted the sceneries A2 - the more pessimist, and B2 - a little more optimist and $-10 \%$ of precipitation during the winter and $+5 \%$ of precipitation during the summer, based on the fourth report of IPCC (2007). For this situations, observed that the climate will be hotter and the drought will be longer. And although the prognostics are of an increase in the precipitation total during the summer, the increase of the temperature will increase of the evapotranspirations demands, and the precipitations index won't be sufficient, increasing the water deficit. Like this, measures should be adopted for a planning of the use and agricultural occupation of the lands, as well as of the sustainable management of water.

Keywords: IPCC. Climate changes. Agricultural. Management of water.

\section{INTRODUÇÃO}

Ter conhecimento do regime hídrico de uma região; da época mais apropriada ao longo do ano para o preparo do solo, semeadura e plantio e a viabilidade de implantação de sistemas de irrigação ou drenagem, são condições imprescindíveis para a prática agrícola, e para isso, torna-se necessário o conhecimento das condições climáticas predominantes, destacando-se a precipitação e a evapotranspiração.

Segundo Pereira et al. (2002) a disponibilidade hídrica pode ser quantificada pelo balanço hídrico climatológico, no qual fica evidenciada a flutuação temporal de períodos com excedente e com deficiência, permitindo, dessa foram, o planejamento das atividades agrícolas e a quantificação da irrigação.

\footnotetext{
${ }^{1}$ Eng. Agrônoma. Dra. Ciência do Solo. Prof. FE/FAFRAM. anice@ feituverava.com.br
} 
No ano de 2007, o Painel Intergovernamental sobre Mudanças Climáticas, IPCC (2007) publicou o quarto relatório a respeito dos avanços da ciência referente às mudanças climáticas globais, no qual são apresentados resultados de modelos de simulação de cenários climáticos futuros. Essas simulações foram realizadas para dois cenários, a saber: Cenário A2 - cenário que descreve um mundo futuro muito heterogêneo no qual a regionalização é dominante, com alto índice de crescimento populacional, e menos preocupação em relação ao desenvolvimento econômico rápido, nesse mundo existirá um fortalecimento de identidades culturais regionais, com ênfase em valores da família e tradições locais; Cenário B2 - cenário que descreve um mundo futuro no qual a mudança tecnológica é mais diversa. A ênfase está em soluções locais, sustentabilidade econômica, social e ambiental, e nas iniciativas comunitárias e inovação social em lugar de soluções globais.

Segundo o relatório, entre 2071 a 2100 a temperatura pode variar entre 4 a $8^{\circ} \mathrm{C}$ na Amazônia, para o cenário A2 e 3 a $5^{\circ} \mathrm{C}$ para o cenário B2, com grande variabilidade espacial. Para a região Nordeste o aquecimento pode chegar a $4{ }^{\circ} \mathrm{C}$ no cenário pessimista $\mathrm{A} 2$ e de 2 a $3^{\circ} \mathrm{C}$ no cenário otimista $\mathrm{B} 2$. No cenário A2 o aquecimento no Centro-oeste e Sudeste pode variar entre 4 a $6^{\circ} \mathrm{C}$, enquanto que o cenário $\mathrm{B} 2$ apresenta valores entre 2 a $3^{\circ} \mathrm{C}$. No Sul o cenário A2 sugere aquecimento da ordem de 3 a $4^{\circ} \mathrm{C}$ e entre 2 e $3^{\circ} \mathrm{C}$ no cenário B2 (Marengo, 2007). Em relação aos padrões projetos de mudanças na precipitação a maioria dos modelos prevêem aumento de precipitação no Brasil durante os meses de verão e diminuição de precipitação durante o inverno.

O objetivo do presente trabalho foi avaliar o balanço hídrico climatológico para Ituverava - SP, sob as condições climáticas atuais e baseados nos cenários climáticos futuros, considerando-se as projeções de aumento de temperatura do quarto relatório de avaliação do IPCC (2007).

\section{MATERIAL E MÉTODOS}

Os dados de precipitação e temperatura do ar para a cidade de Ituverava-SP $\left(20^{\circ} 20^{\prime} 22^{\prime \prime}\right.$ S, 4746'50" W e 605 m), cujo clima de acordo com a classificação de Köppen, é Aw, com verão úmido e inverno seco (CARRER; GARCIA, 2007), foram obtidos na Estação Agrometeorológica da Faculdade Dr. Francisco Maeda (FAFRAM) e referem-se a um período de 12 anos (1996-2008).

Esses dados foram utilizados na elaboração do balanço hídrico climatológico, empregando-se o método de Thornthwaite; Mather (1955), através do programa "BHnorm" elaborado em planilha EXCEL® por Rolim et al (1998). A capacidade de água disponível 
(CAD) utilizada para a confecção dos Balanços Hídricos foi de $100 \mathrm{~mm}$. Como resultado, o balanço hídrico forneceu as estimativas da evapotranspiração real (ETr), da deficiência hídrica (DEF), do excedente hídrico (EXC) e do armazenamento de água no solo (ARM) para cada mês do ano.

Os Balanços foram realizados para três condições distintas: o BHC normal, com dados de 12 anos, o BHC com dados simulados de mudanças climáticas. Adotou-se os cenários A2 o mais pessimista, que estima um aumento de temperatura de $4,0^{\circ} \mathrm{C}$ até 2100 - e o B2 - um pouco mais otimista, que prevê um aumento de temperatura de até $2,0^{\circ} \mathrm{C}$ em 2100 . Com relação a precipitação, adotou-se as previsões de $-10 \%$ de precipitação durante o inverno e $+5 \%$ de precipitação durante o verão.

\section{RESULTADOS E DISCUSSÃO}

Na Figura 1, 2 e 3 são apresentados os Balanços Hídricos climatológicos, para as três situações propostas.
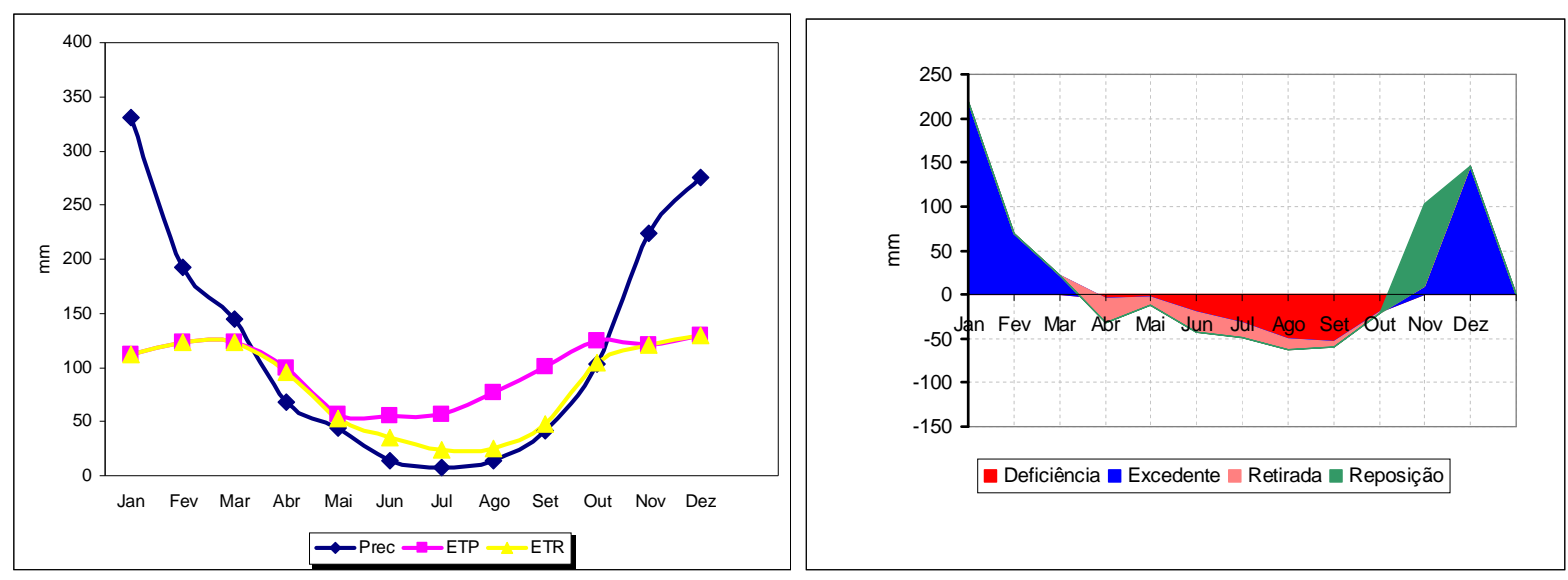

Figura 01 - Balanço Hídrico Segundo Thorntwaite \& Mather - 1955. CAD: 100 mm NORMAL (1996-2008).
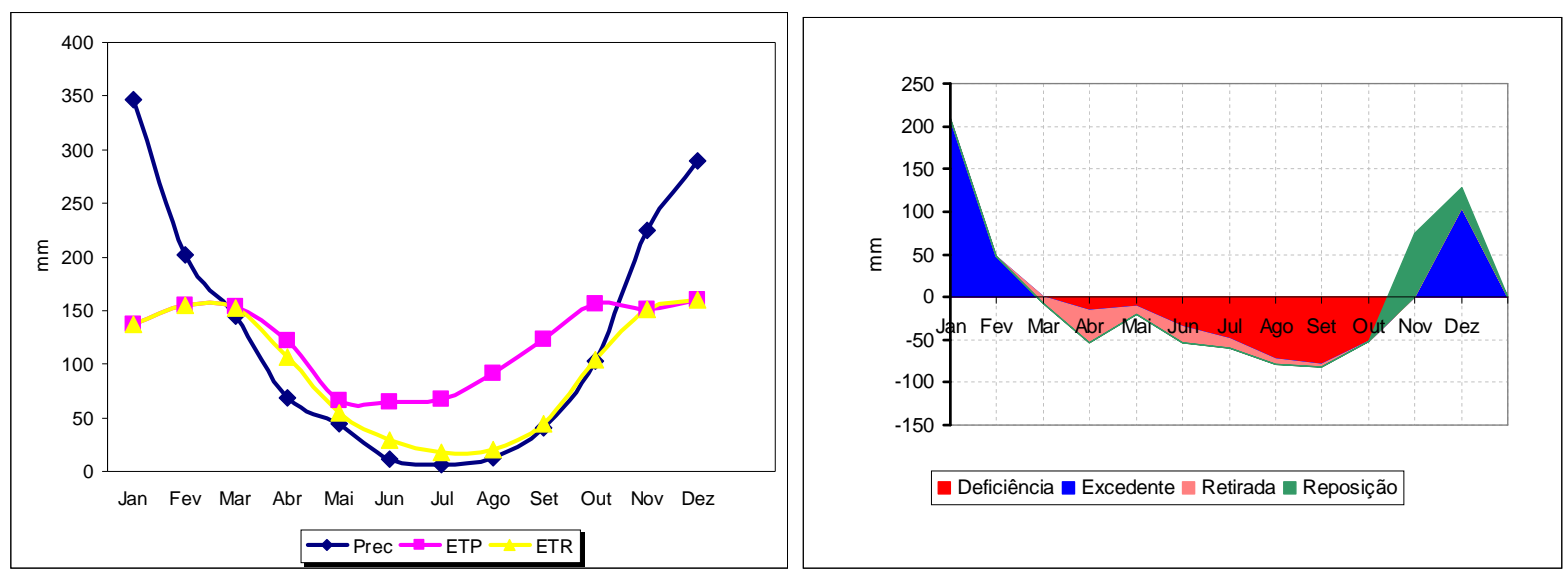

Figura 02 - Balanço Hídrico Segundo Thorntwaite \& Mather - 1955. CAD: $100 \mathrm{~mm}$ Cenário de Mudanças Climáticas $\left(\mathrm{B} 2:+2^{\circ} \mathrm{C},+5 \%\right.$ Prec. Verão e $-10 \%$ Prec. Inverno). 

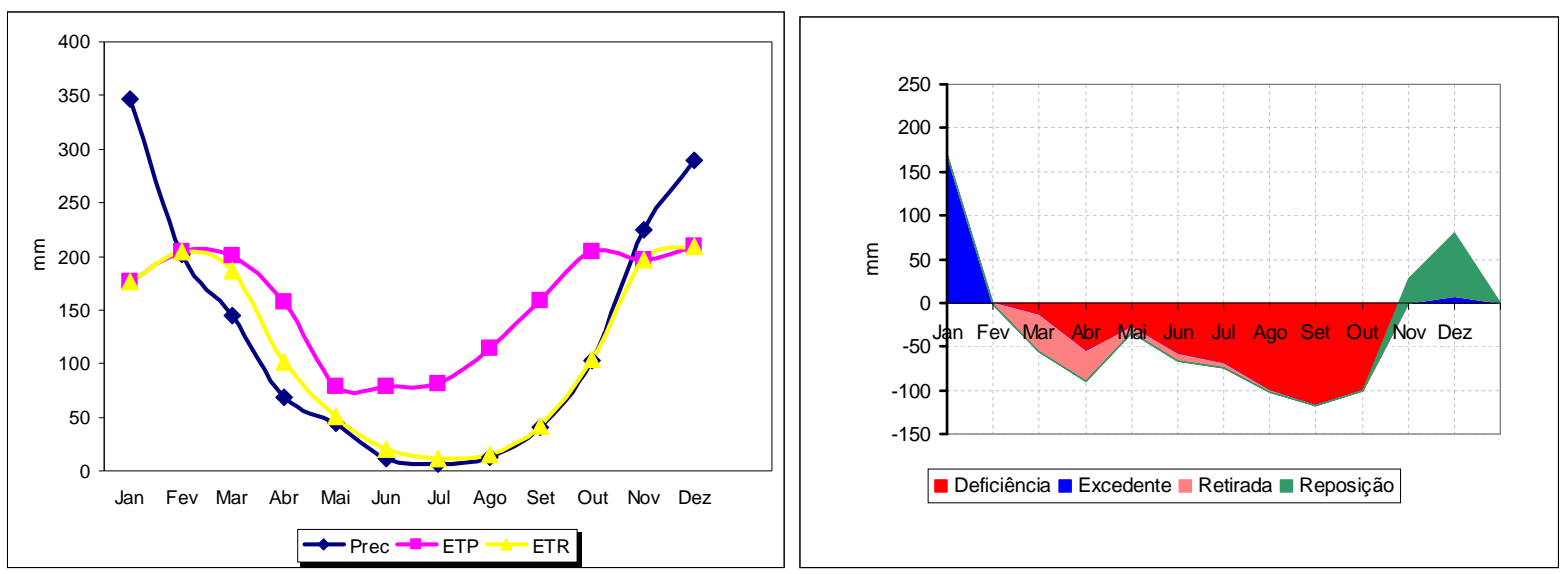

Figura 03 - Balanço Hídrico Segundo Thorntwaite \& Mather - 1955. CAD: $100 \mathrm{~mm}$ Cenário de Mudanças Climáticas $\left(\mathrm{A} 2:+4^{\circ} \mathrm{C},+5 \%\right.$ Prec. Verão e $-10 \%$ Prec. Inverno).

Através do balanço hídrico climatológico normal (Figura1), pode-se perceber que uma elevada precipitação anual não significa que a região esteja livre de períodos de deficiência hídrica. Assim, em Ituverava- SP, onde a precipitação total - média atinge (aproximadamente) $1460 \mathrm{~mm}$, verifica-se uma deficiência hídrica em torno de $184 \mathrm{~mm}$ nos meses de abril a setembro, e um excedente hídrico de $464 \mathrm{~mm}$ nos meses de novembro a março. Como é característico para a região sudeste do Brasil, as chuvas se concentram no verão (56\%), sendo escassas durante o inverno (2\%). A primavera contribui com $22 \%$ das chuvas anuais e o outono com $20 \%$.

O balanço Hídrico com os prognósticos mais otimistas do relatório do IPCC (cenário B2) (Figura 2), mostra que a evapotranspiração aumenta, uma vez que ela é função da temperatura do ar. A diferença entre a evapotranspiração potencial e a real, também aumenta, causando um aumento no déficit hídrico, que passa a ser de $313 \mathrm{~mm}$ ( $70 \%$ acima do $\mathrm{BH}$ normal), além disso, as deficiências de água no solo se prolongam iniciando em março e terminando em meados de outubro (período seco), esse resultado mostra ser praticamente impossível as culturas de sequeiro, que requerem uma grande quantidade de água e temperaturas mais amenas.

Pelo balanço Hídrico com os prognósticos mais pessimistas do relatório do IPCC (cenário A2) (Figura 3), nota-se um comportamento similar, porém mais pronunciado. Há um a reposição hídrica nos meses de novembro e dezembro, com excedente hídrico ocorrendo no mês de janeiro. O período de deficiência hídrica vai de fevereiro a outubro, totalizando 545 $\mathrm{mm}$, (quase $200 \%$ superior ao $\mathrm{BH}$ normal), o que inviabilizaria quaisquer culturas sem a suplementação hídrica com uso de irrigação. 


\section{CONCLUSÃO}

Para ambos os cenários estudados, observa-se que o clima estará mais quente e a estiagem será mais longa. E embora os prognósticos sejam de um aumento no total de precipitação durante o verão, o aumento da temperatura provocará um aumento dos níveis de evapotranspiração, que não conseguirão ser supridos com a precipitação ocorrida, aumentando o déficit hídrico. Assim, medidas deverão ser adotadas para um re-planejamento do uso e ocupação agrícola das terras, bem como do manejo sustentável da água.

\section{REFERÊNCIAS}

CARRER, T.; GARCIA, A.. Classificação climática para a cidade de Ituverava/SP. Nucleus, Ituverava: FE/Ituverava, v.4, n.1, p. 29-37, 2007.

IPCC (2007). IPCC Fourth Assessment Report. Climate Change 2007: The Physical Science Basis - Summary for Policymakers. Contribution of Working Group I to the Fourth Assessment Report of the Intergovernmental Panel on Climate Change. Richard Alley, T. Berntsen, N. L. Bindoff, Z. Chen, A. Chidthaisong, P. Friedlingstein, J. Gregory, G. Hegerl, M. Heimann, B. Hewitson, B. Hoskins, F. Joos, J.Jouzel, V. Kattsov, U. Lohmann, M. Manning, T. Matsuno, M. Molina, N. Nicholls, J. Overpeck, D. Qin, G. Raga, V. Ramaswamy, J. Ren, M. Rusticucci, S. Solomon, R. Somerville, T.F. Stocker, P. Stott, R.J. Stouffer, P. Whetton, R.A. Wood e D.Wratt. IPCC Secretariat at WMO, Geneva, Switzerland, http://www.ipcc.ch

MARENGO, J. Mudanças climáticas globais e seus efeitos sobre a biodiversidade: caracterização do clima atual e definição das alterações climáticas para o território brasileiro ao longo do século XXI. 2. ed. Brasilia: Ministério do Meio Ambiente, 2007b. v. 1 , p. 214

PEREIRA, A.R.; ANGELOCCI, L.R.; SENTELHAS, P.C. Agrometeorologia: fundamentos e aplicações práticas. Guaíba: Agropecuária, 2002. 478p.

ROLIM, G.S.; SENTELHAS, P.C.; BARBIERI, V. Planilhas no ambiente EXCEL para os cálculos de balanços hídricos: normal, sequencial, de cultura e de produtividade real e potencial. Revista Brasileira de Agrometeorologia, Santa Maria, v.6, p.133-137, 1998.

THORNTHWAITE, C.W.; MATHER, J.R. The water balance. Centerton, NJ: Drexel Institute of Technology - Laboratory of Climatology, 1955. 104p. (Publications in Climatology, vol. VIII, n.1). 
